\section{Energy in the OECD}

G. R. Bainbridge, Professor of Energy Studies and Director of The Energy Centre, University of Newcastle upon Tyne, reflects on the OECD report, Energy Prospects to 1985.

WHEN, in 1972, the council of the OECD initiated an assessment of energy developments and related policies it was anticipating that the projected growth of energy demand in the 24 countries constituting the OECD area would put increasing pressure on low cost energy supplies. It was particularly concerned about future supplies of oil from the Middle East, where $90 \%$ of the world's petroleum trade originates and where $55 \%$ of the proven natural oil reserves lie.

Moreover the USA, using a third of the 5,000 million tons of oil equivalent world annual energy consumption, was becoming increasingly an oil importer. Indeed only two OECD countries, Canada (trading oil and gas for coal) and Australia (trading coal for oil) have net total energy self sufficiency. So the pressure of oil demand would inevitably have important implications for the economies and policies of most OECD members, 15 of whom are dependent for $70 \%$ or more of their energy needs on imports, and only some of whom (the USA, Norway, the Netherlands and UK) could with sustained effort join the select group of those reasonably self sufficient in energy.

The concerted oil export restrictions applied by OPEC towards the end of 1973, followed by a dramatic increase in crude oil prices, came as a shock, emphasising the timeliness of the OECD energy exercise. It was clear that the prospects for a return to an era of relatively cheap energy had "dwindled considerably".

It is not surprising that the OECD assessors found themselves unable to provide probable, or target, projections of energy supply and demand, even for 10 years ahead, while initiatives were and still are being taken by the oil suppliers and consumers almost daily. They made, instead, a brave attempt to present in a qualitative way the principal likely determinants of future development of the energy sector. Increasing gross national production would be expected to require more energy, though perhaps not too much more if the trend towards improved energy-efficient processes continues and the likely substitution of capital and labour for more costly energy use occurs.

The price of energy had scarcely before been considered explicitly as a factor influencing energy demand, because prices were low and fairly stable. Now it had become the main one. In obtaining estimates of future energy use, oil prices rising from the early 1973 baseline of $\$ 3$ (USA 1972 money) a barrel ( 7 barrels $\sim 1$ tonne) to $\$ 6$ and $\$ 9$ were taken to provide a framework for investigating the implications for other economic factors and to identify possible problems that might confront the policymaker. Without criticism they could have gone even higher with the alternatives. During the period of the exercise, of course, dollar depreciation made those prices selected $\$ 3.60, \$ 7.20$ and $\$ 10.80$ by the end of 1974 . Inflation is only one of several factors listed in the recent Solemn Declaration of the Sovereigns and Heads of State of the OPEC member countries for consideration by them when adjusting crude oil prices in future.

By comparison with growing gross national product and primary fuel prices the other determinants of energy supply and demand tend to fade into insignificance, particularly in the next worrying decade of readjustment. Measures already taken or planned to improve environmental protection were found to tend to increase energy consumption, albeit by only a few percent. Although some of them have already been relaxed or left in abeyance to ease the energy crisis, "efforts towards energy savings, if successful, could enable environmental protection measures to be resumed.

As might be expected the main part of the OECD report concentrates on the prospects for the provision of oil, coal, natural gas, electricity and nuclear power in the near future. The possibility of greater indigenous production within the OECD is considered particularly important, with nuclear fission, North Sea oil and gas, and rejuvenation of coal and its synthetic products being all seen to have useful parts to play.

In order to broaden the options for future choices, and to open up greater possibilities for the diversification of energy supplies, continuing research and development efforts directed towards exploitation of some of the renewable resources are recommended in the report. The contributions from solar energy and further geothermal energy were recognised to be expected in general beyond 1985 . Research into the derivation of fuels from towns' wastes and the productions of methanol and hydrogen was also recommended, with thermonuclear fusion as the piece de resistance for the long term. Little was said of wind and wave power, or ocean thermal gradients, as an energy source, perhaps because the prevailing Southwesterlies and the Gulf Stream have apparently been veering a little off course of late.

Anyone preparing to read this very informative OECD report should apply initial energy to acquiring a good magnifying glass, as the many and interesting tables in the key chapters 2 (Energy Demand and Supply Projections) and 3 (Economic and Environmental Implications) are printed minutely. Chapter 4, on Energy Conservation, is appropriately of below average length, but that glass is needed again for the vital table which analyses energy conservation possibilities; but the effectively blank four pages immediately preceding the chapter emphasise the scope there is for workers in the energy field to practise what they preach. More than $5 \%$ of the 224 pages in Volume 1 carry no significant point and the proportion is higher in Volume 2.

Because of the dominance of US energy consumption (and production) in any overall OECD energy trends, it was correct that the USA should be treated separately. In 1972 the USA was using $50 \%$ more primary energy than the 19 European OECD members together, and its indigenous production was three times greater than theirs. Separate consideration of Canada was also useful, for, although it uses only a tenth as much energy as the USA, its surpluses of oil and natural gas will increasingly be directed southwards. Japan (also separately treated) already imports more energy than the USA and in future will continue as a major competitor for the world's oil, coal and natural gas resources-unlike the USA, Japan has little scope for indigenous production and has a higher growth rate for both population and gross national product.

The EEC is included for statistical comparison in some of the tables of the report. The strength of the EEC compared with the OECD European 19 lies in the fact that the smaller grouping contains the major industrial countries, using well over $50 \%$ of the primary energy, producing over $70 \%$ of the European indigenous fuel supplies and with the better natural potential to improve on that position if pressed. The energy strength of the EEC might have been further improved by Norway, but that country chose through a referendum to opt out; it has indigenous North Sea oil and gas production potential of the same order as the UK, but a very much smaller population already well endowed with hydro-power resources.

The figure summarises historical behaviour and possible alternative trends 
of future OECD energy requirements. Had world oil prices not increased, the doubling time for energy consumption would be running at about 15 years, some $4.9 \%$ a year. Although the OECD, with present energy consumption running at a little over 3,500 million tons of oil equivalent a year, accounts for about $70 \%$ of world usage, the developing countries outside the OECD group will tend to bias world growth to a higher rate and a shorter doubling time. With the oil import price increased by factors of 2 and 3 , some energy savings are anticipated to bring OECD growth down to $4.3 \%$ a year and $3.8 \%$ a year respectively. Then, at 1985, the higher oil prices have depressed energy use (or encouraged desirable energy savings) to the extent of $7 \%$ and $12 \%$ respectively, on the total. The nuclear, coal and gas proportions are all increased for the higher oil prices, relative to oil.

Some of the immediate broad conclusions could have been deduced by intuition almost as easily as from detailed analysis, namely:

- The OECD share of oil is expected to decline to below $50 \%$ of total energy requirements from around $55 \%$, though its use is still increasing steadily at 1985 and seems likely to have reached at least 2,800 million tons of oil equivalent a year, compared with 2,000 million tons of oil equivalent a year today. The increment alone is a factor of 4 higher than the anticipated oil yield from the North Sea.

- The natural gas share grows on balance, the percentage increment in Europe compensating for a relative decline in use in the USA. Although the percentage stays around the $22 \%$ mark, the annual use almost doubles from 600 to about 1,200 million tonnes of oil equivalent. It should be noted that natural gas is being increasingly supplied into the Eurogas grid from Russia and Holland; soon additional supplies will come nonth from Africa by undersea pipeline by way of Italy, supplementing present liquid natural gas trans-shipments.

- Nuclear power is expected to play a steadily increasing role, rising (including a small component of hydro) from around $4 \%$ of total energy now to some 8 to $10 \%$ by 1980 and 12 to $16 \%$ by 1985 . As might be expected, therefore, the nuclear doubling time is of the order 5 to 7 years, below half that for total energy. This is significant in view of the long lead times for power station construction, and must depend on policy decisions already taken in many countries to press on more quickly with nuclear programmes in view of the higher oil prices.
The use trend for coal is expected to increase again, reversing a steady decline after the Second World War. European coal resources are mainly in Germany (brown) and the UK (black) but the USA still has vast and relatively easily worked coal deposits. It is there and in Australia that the most likely prospect for greatly raising coal production arises, though in Europe an increase of 10 to $20 \%$ seems to be a sufficiently challenging and achievable target.

The analysis leading to the projections does not seem to have allowed for the probability that coal and natural gas prices are bound to rise to what the market will bear for these fuels, relative to the oil price, or that nuclear capital costs will escalate because of the effect of increased conventional fuel and labour costs on manufacture. These occurrences will depress the demand for fuels alternative to oil, and the supply of oil may exceed demand sufficiently for selling competition to re-enter the market. The report is right to suggest that, because the energy pattern of the OECD and indeed the world, is a dynamic one, continuing study to achieve a better understanding of it is worthwhile. For example, OECD oil imports in 1980 could easily be $70 \%$ higher than now if savings of energy use, substitution of other energy forms and restriction of national product outputs are not effected. Higher oil prices, if sustained, could, however, reduce the extra import demand to below $20 \%$ and cause even a reduction of the amount of imponted oil and expenditure on it, ignoring any oil suppliers' price adjustments to optimise their returns.

Actions recommended to OECD members to improve the arrangements for cooperation in energy and related fields, inter-regional (EEC and OECD Europe) and intra-regional (EuropeNorth America, Europe-Far East) if possible, seem laudable; emergency energy-sharing schemes, promotion of energy trade, energy savings schemes, energy research and development to ensure adequate supplies at reasonable cost all need work. Inflation, and the sorting out of balance of payments problems, are current international problems needing OECD support.

A bringing together of the oilexporting and oil-importing countries in agreed policies for mutual and world benefit is another area recommended for OECD action, with joint studies of problems to find agreed solutions which will bring greater stability to the energy and money markets. The idea that scientific and technical assistance should flow from countries with the capability towards those that need to develop is one on which OECD and OPEC representatives should be coming close together.

In the UK Parliamentary debate on the EEC energy proposals early in February of this year it was concluded that as trade with our partners becomes more interdependent there is obvious sense in seeking to evolve coordinated energy policies. The OECD report firmly confirms that view.

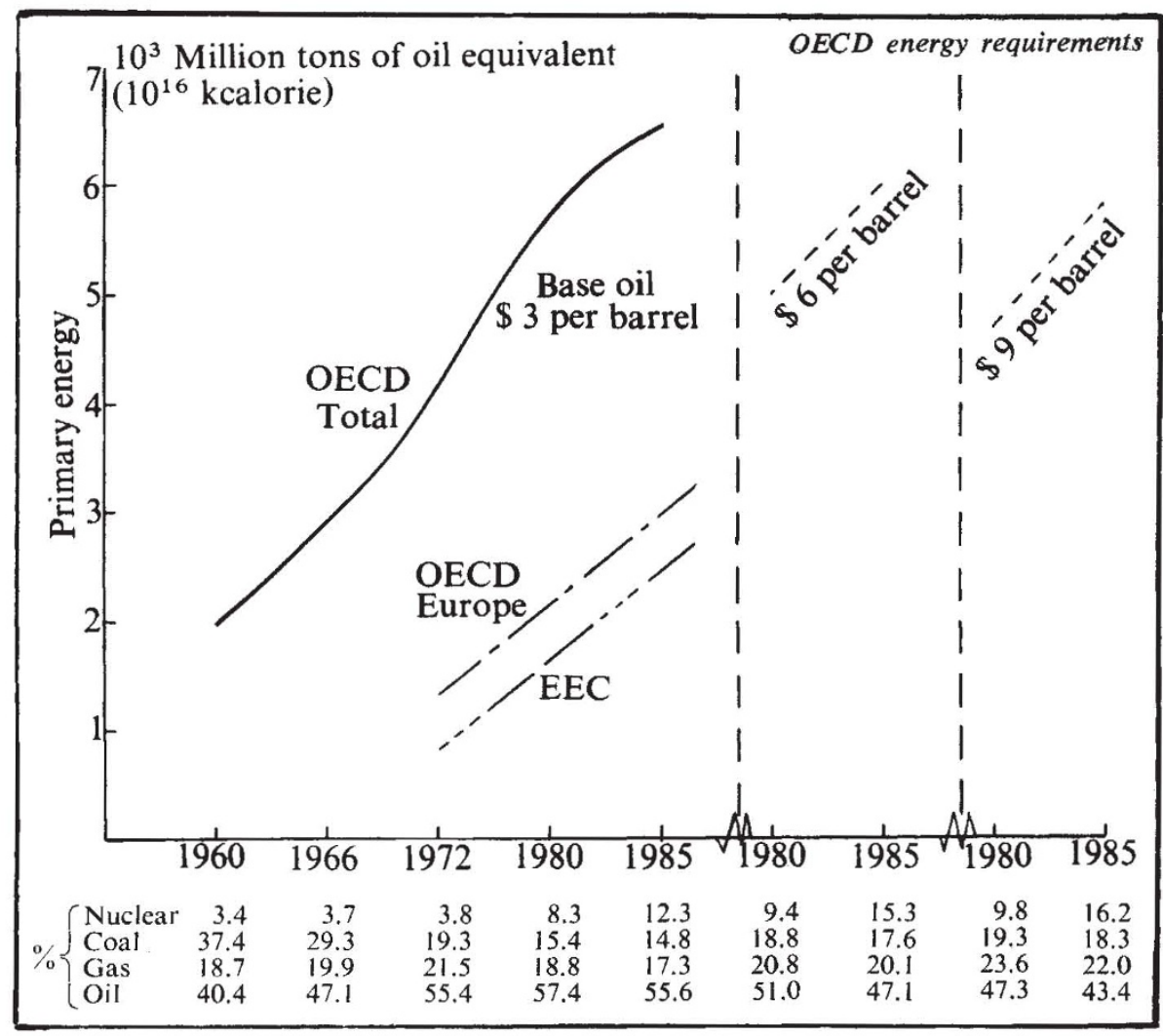

